\title{
ОЦІНКА ЕФЕКТИВНОСТІ РЕАБІЛІТАЦІЙНИХ ЗАХОДІВ НА ОСНОВІ МКФ-ПРОФІЛЕЙ ПАЦІЕНТІВ
}

Горборуков В. В.

\author{
Національний університет «Києво-Могилянська академія», м. Київ, Украӥна
}

\begin{abstract}
Для кореспонденції: Горборуков Вячеслав Вікторович, кандидат технічних наук, доцент кафедри мультимедійних систем Національного університету «Києво-Могилянська академія», вул. Г. Сковороди, 2, м. Київ, 04070, Україна; e-mail: slavon07@gmail.com; контактний тел.: +38 (044) 4257753.
\end{abstract}

Реабілітація є важливою стратегією охорони здоров'я і розглядається як комплекс заходів, спрямованих на допомогу особам з обмеженнями життєдіяльності для досягнення $і$ підтримання оптимального функиіонування у взаємодії 3 навколишнім середовищем. Визначення у пацฺієнтів реабілітаційного потенціалу та оцінка ефективності реабілітації $\epsilon$ необхідною умовою для формування правильної реабілітаційної стратегії. Сучасним міжнародним інструментом, щьо визначає принщипи прогнозування результатів реабілітації, оцінки реабілітаційного потенціалу та побудови реабілітаційних програм є Міжнародна класифікачія функиіонування, обмежень життєдіяльності та здоров'я (МКФ). Впровадження даних принцииів дозволяє зробити прозорим процес реабілітації, щзо сприяє підвищенню якості медичної допомоги. Але крім оцінок за ичими шкалами, необхідне використання певного методу визначення на їх основі індикативної інтегральної величини, шяо характеризує реабілітаційний потенціал пацієнта та його здатність до одужання.

Мета дослідження полягала у виробленні науково-методичного підходу визначення ефективності реабілітаційних заходів на основі МКФ-профілей пацієнтів та програмної реалізації даного підходу у вигляді інформаційно-аналітичної системи.

В роботі розглянуто сучасний стан способів оичінки реабілітаційного потенціалу та ефективності реабілітації на основі міжнародного стандарту МКФ. Проаналізовано апробовану методику оцінки ефективності реабілітації на основі обрахунку реабілітаційного інтегрального показника з точки зору можливості ї̈ вдосконалення та формалізації у вигляді певної математичної моделі. Програмна реалізація системи оцінки ефективності реабілітації створювалась за допомогою відповідних шаблонів проектування та на основі об'єктно-орієнтованого підходу.

В результаті роботи вдосконалено методику оцінки ефективності реабілітаційних заходів та створено ї̈ математичну модель, щьо дозволяе оцінити комплексний результат реабілітаиії, використовуючи основні категорії МКФ. Розроблено програмну систему оцінки ефективності реабілітації на основі МКФ-профілей пацієнтів, яка дозволяє проводити комплексну аналітику процесу їх відновлення. Зокрема, система надає наступні можливості: визначити реабілітаційний потенціал пацієнта, щзо дозволяє оцінити його потенційну можливість до відновлення; встановити реабілітаційний інтегральний показник після курсу реабілітації, щзо дозволяе визначити рівень реалізації початкового реабілітаційного потенціалу та ступінь відновлення компенсаторних можливостей; проаналізувати динаміку зміни оцінок по МКФ-доменам та виявити найбільш проблемні напрямки.

Отже використання створеної програмної системи оцінки ефективності реабілітації на основі МКФ-профілей пацієнтів дозволяс оцінити реабілітаційний потенціал у кожного конкретного пацієнта, визначить його потребу в реабілітаційних послугах, відстежить динаміку і оцінити ефективність відновного лікування та реабілітації в цүілому.

Ключові слова: міжнародна класифікація функиіонування, ефективність реабілітації, реабілітаційний потениіал, програмна система.

Вступ. Сучасним міжнародним інструментом, що визначає принципи прогнозування результатів реабілітації, оцінки реабілітаційного потенціалу та побудови реабілітаційних програм $є$ Міжнародна класифікаціяфункціонування,обмеженьжиттєдіяльності та здоров'я $[9,15]$. МКФ визначила чинники, що характеризують здоров'я, враховувала порушення структур, функцій, обмеження життєдіяльності і такзвані контекстні фактори, що враховують стан середовища та особистісні чинники [14]. МКФ являє собою інструмент для забезпечення уніфікованого підходу в реабілітації, за рахунок чого фахівці 3 різних спеціальностей $\mathrm{i}$ медичних установ можуть розуміти один одного, та дозволяе на практиці реалізувати базові принципи реабілітації: пацієнт-центрований та проблемноорієнтований принципи, персоналізований підхід, мультидисциплінарний принцип, біопсихосоціальну модель хвороби та інвалідності $[12,19]$.

Для лікарів клініцистів одним з головних критеріїв використання МКФ $є$ можливість сформулювати реабілітаційний діагноз, який в свою чергу дозволяє визначити мету, завдання, програму реабілітації, а в подальшому оцінити ефективність реабілітаційних заходів. Застосування МКФ в практиці установи створює можливості для ефективного міждисциплінарної взаємодії на основі єдиної системи категорій для планування і проведення реабілітаційних заходів $[10$, $11,13,21]$.

Міжнародна класифікація функціонування, обмежень життєдіяльності та здоров'я дозволяє об'єктивно визначити стан здоров'я пацієнтів і вибрати технічні засоби реабілітації в залежності від ступеня обмежень життєдіяльності для дорослого населення $[1,20]$. 
Необхідно відзначити, що формування правильної стратегії реабілітації потребує визначення реабілітаційного потенціалу пацієнта. Реабілітаційний потенціал - це комплекс біологічних i психологічних характеристик людини, а також соціально-середовищних факторів, що дозволяють в тій чи іншій мірі реалізувати його потенційні можливості [16]. Оцінка реабілітаційного потенціалу має на меті визначення різних характеристик індивідуума. Його визначення необхідно не тільки для правильної побудови реабілітаційної програми, але i для прогнозування ефективності проведених реабілітаційних заходів, оцінки рівня можливого відновлення порушених функцій [17].

Мета дослідження полягала у виробленні науковометодичного підходу визначення ефективності реабілітаційних заходів на основі МКФ-профілей пацієнтів та програмної реалізації у вигляді інформаційно-аналітичної системи..

Матеріали і методи. В даний час МКФ $є$ міжнародним стандартом (рис. 1) для проведення досліджень, опису стану пацієнтів, постановки цілей реабілітації, оцінки реабілітаційного потенціалу, організації відновного процесу i оцінки його результатів. Його застосування дозволяє оцінити ступінь вираженості порушень функцій організму і передбачає їх розгляд у взаємодії з персональними характеристиками i факторами навколишнього середовища $[13,16,18,20,22]$.

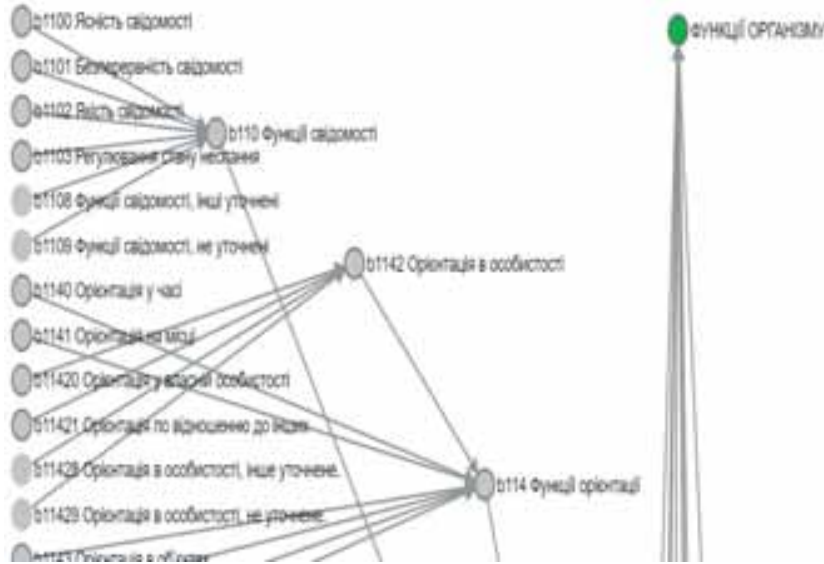

Рис. 1. Онтологія «Міжнародна класифікація функціонування»

Однак існує необхідність у напрацюванні підходу для обрахунку узагальненого інтегрального показника реабілітаційного потенціалу на основі МКФ-профіля пацієнта для оцінки стану пацієнта та ефективності проведеної реабілітації. Така методика була запропонована, де спосіб оцінки ефективності реабілітації пацієнтів визначається шляхом вимірювання показників порушень функцій організму, активності і участі пацієнта за допомогою стандартизованих оціночних шкал категорії «Міжнародної класифікації функціонування, обмеження життєдіяльності та здоров'я» [17].
Ця методика оцінки реабілітаційного потенціалу пацієнта та реабілітаційного інтегрального показника після курсу реабілітації дозволяе встановити ефективність проведеної реабілітації. Визначення інтегрального реабілітаційного показника у пацієнтів в пізньому відновлювальному періоді відображає ступінь реалізації початкового реабілітаційного потенціалу. Таким чином низькі значення свідчать про те, що реабілітаційний потенціал не реалізований або реалізований частково, високі ж значення вихідної реабілітаційної оцінки свідчитимуть про те, що до даного рівня відновлення пацієнти змогли реалізувати більшу частину своїх компенсаторних можливостей.

Враховуючи, що відповідна методика була успішно апробована на практиці, то необхідно провести іiі аналіз на потенційну можливість вдосконалення та програмно реалізувати у системі оцінки ефективності реабілітації за допомогою відповідних шаблонів проектування $[3,6]$ та на основі об'єктно-орієнтованого підходу створення програмного забезпечення [2].

Для ефективної розробки Web-орієнтованих застосувань та їх подальшій експлуатації в програмній інженерії використовується трирівнева архітектура [4, 5]. Багаторівнева архітектура, яка дозволяє інтегрувати нові технології та долучати інші компоненти без необхідності перепроектовувати все програмне забезпечення, змінювати іiі програмний код та існуючі компоненти, що в свою чергу полегшує вирішення проблем масштабування та підтримки.

Результати. В ході роботи 3 точки зору багатокритеріального аналізу була досліджена методика [17] визначення реабілітаційного інтегрального показника та створено узагальнену трирівневу математичну модель, що включає вищезазначену методику в якості певного часткового випадку.

Нехай розглядається деяка ієрархічна система (рис. 2) з трьох рівнів ієрархії. Значення показників нижнього рівня ієрархії що утворюють $m$ різних груп узагальнюється спочатку по кожній групі (другий рівень) і наприкінці - в узагальнений показник $G$. Для задання значень показників $g_{i j}$ кожної групи

$$
i, \quad i=\overline{1, m}, \quad i=\overline{1, n_{i}}
$$

використовується певна бальна шкала $B=\{0,1,2, \ldots, b\}$ (наприклад, $B=\{0,1,2, \ldots, 9\})$.

В загальному випадку важливість

$$
V_{i}=\left(v_{i 1}, \ldots, v_{i n_{i}}\right), \quad \sum_{j=1}^{n_{i}} v_{i j}=1, v_{i j} \geq 0,
$$

показників $g_{i j}$ може бути різною. Аналогічно, показники другого рівня ієрархії $f_{i}$ також можуть характеризуватись своїм вектором переваг

$$
\left.W=\left(\omega_{1}, \ldots, \omega_{m}\right)\right), \quad \sum_{j=1}^{m} \omega_{j}=1, \omega_{j} \geq 0
$$

i по різному впливати на загальний показник верхнього рівня $G$. 


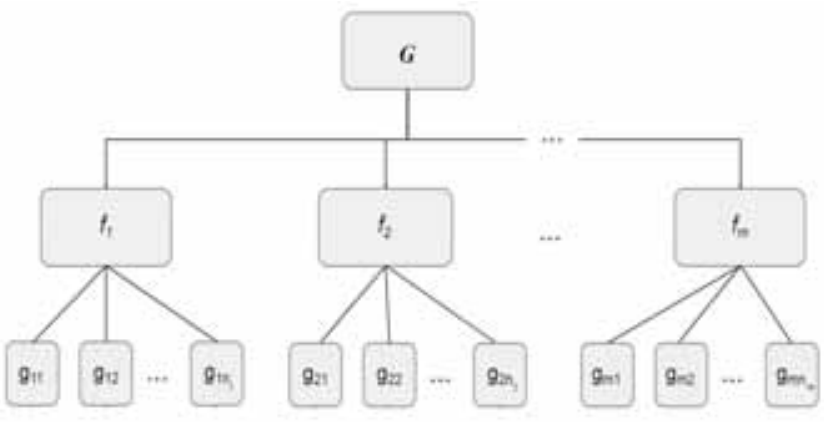

Рис. 2. Ієрархічна структура формування узагальненого показника $G$

Таким чином, можна розглянутизадачу обчислення значень показників верхніх рівнів, як деяких функцій над числовими значеннями $g_{i j}$. Безпосередньо ці функції та процедури обчислення визначаються відповідною методикою, що застосовується в тому чи іншому випадку.

Отже, формально модель сформульованої задачі можна представити так:

$$
\begin{aligned}
& f_{i}=f_{i}\left(\left(g_{i 1}, \ldots, g_{i n_{i}}\right),\left(v_{i 1}, \ldots, v_{i n_{i}}\right)\right), i=1, m \\
& f_{i}=f_{i}\left(\left(g_{i 1}, \ldots, g_{i n_{i}}\right),\left(v_{i 1}, \ldots, v_{i n_{i}}\right)\right), i=\overline{1, m} \\
& V_{i}=\left(v_{i 1}, \ldots, v_{i n_{i}}\right), \quad \sum_{j=1}^{n_{i}} v_{i j}=1, v_{i j} \geq 0, i=\overline{1, m} \\
& W=\left(\omega_{1}, \ldots, \omega_{m}\right), \quad \sum_{j=1}^{m} \omega_{j}=1, \omega_{j} \geq 0 \\
& g_{i j} \in B=\{0,1,2, \ldots, b\}, \quad i=\overline{1, m}, \quad i=\overline{1, n_{i}}
\end{aligned}
$$

тоді вищерозглянута методика [17] буде мати наступний вигляд:

$$
G=G(F, W)=1-\sum_{i=1}^{m} \omega_{i} f_{i}(\cdot)
$$

де $f_{i}=\frac{g_{i}}{b}, g_{i} \in B=\{0,1,2, \ldots, b\}, \omega_{i}=\frac{1}{m}, \quad i=\overline{1, m}$

$$
\left(g_{i}-\right.\text { значення показника) }
$$

Таким чином розроблена математична модель (1)(5) має наступні переваги: показники при формуванні узагальненого значення можуть мати різну важливість, передбачена можливість ієрархічної структури показників та функції згортки може бути визначена у інший спосіб.

Розроблена програмна системи оцінки ефективності реабілітаційних заходів була спроектована на основі трирівневневої архітектури (рис. 3).

До основних програмних компонентів даної системи, що забезпечують логіку іiі роботи відноситься:

1) блок контролерів - містить в собі контролери

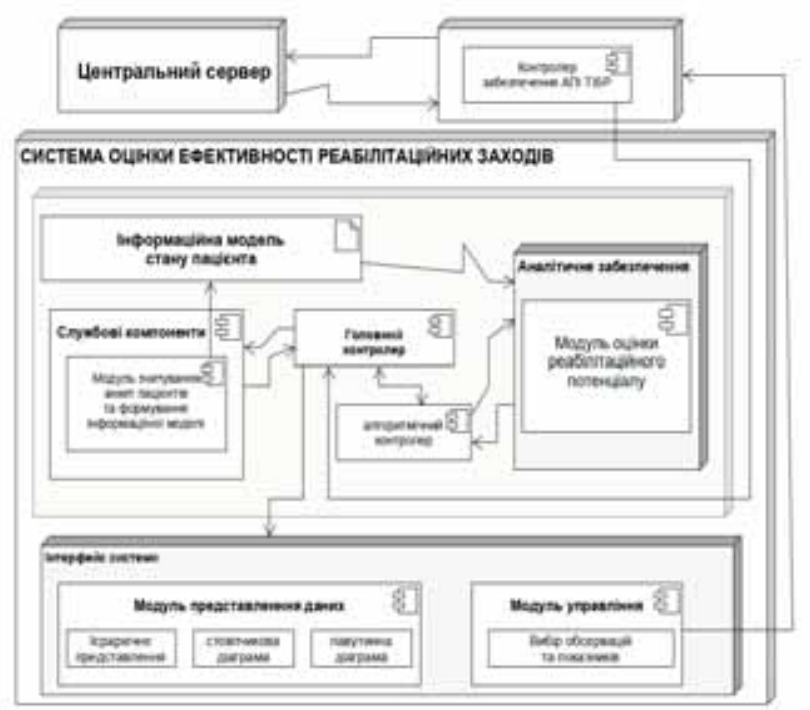

Рис. 3. Архітектура системи оцінки ефективності реабілітаційних заходів.

системи, які відповідають за обробку вхідних запитів, що надходять до системи;

2) модуль зчитування анкет пацієнтів - здійснює формування внутрішньої інформаційної моделі стану пацієнта для ㄲï подальшої обробки згідно відповідних медичних методик; Цей модуль зчитування анкет паціснтів (МКФ-профілей) за допомогою відповідного TISP-програмного інтерфейсу (що забезпечує системну взаємодію) дозволяє отримати необхідну інформацію $з$ картки пацієнта про його стан і результати обстежень, та перетворити іiї у внутрішній формат для подальшого застосування. До основних функцій цього модуля можна віднести: зчитування інформації 3 картки пацієнта про його стан (до та після реабілітації) на основі встановленого протоколу взаємодії з TISPсередовищем; формування інформаційної моделі, яка в себе включає: стан пацієнта до і після реабілітації, визначення МКФ-показників за якими проводилось оцінювання та їх ієрархічну структуризацію на основі онтології міжнародної класифікації функціонування; надання доступу до сформованої інформаційної моделі 3 можливістю отримання та долучення додаткової інформації в модель даних.

3) математичне ядро системи - містить в собі алгоритмічне забезпечення, яке виконує обчислення інтегральних реабілітаційних показників та $\epsilon$ основою аналітичного забезпечення системи.

До основних функцій математичного ядра системи варто віднести:

- встановлення реабілітаційного потенціалу до курсу реабілітації пацієнта. Реабілітаційний потенціал нормалізується у шкалу від 0 до 1 , що дозволяє отримувати єдине значення незалежно від кількості використовуваних шкал, а також порівнювати співвідношення показників у спільній шкалі (максимальний реабілітаційний потенціал дорівнює 1). 
- $\quad$ розрахунок реабілітаційного інтегрального показнику після курсу реабілітації, який характеризує ступінь відновлення компенсаторних спроможностей.

- оцінка якості реабілітації, що вимірюється у відсотковій шкалі та має наступну лінгвістичну градацію: «без динаміки», «задовільна», «хороша» та «дуже хороша»

Інтерфейс системи складається 3 наступних основних модулів:

1) модуль представлення даних - дозволяє здійснити візуальне відображення стану пацієнта до та після реабілітації в різних режимах;

2) модуль управління - в собі містить елементи інтерфейсу, які дозволяють керувати опціональними параметрами.

Основною задачею користувацького інтерфейсу системи оцінки ефективності реабілітаційних заходів є візуалізація стану пацієнта до та після курсу реабілітації і визначення якості реабілітації на основі відповідної методики. Крім цього інтерфейс має забезпечувати можливість вибору обсервацій пацієнту, які застосовувати для аналізу. В ході роботи був створений відповідний веб-інтерфейс (рис. 4), що надає відповідну функціональність.

Розроблений інтерфейс системи дозволяє користувачеві виконувати наступні операції:

- $\quad$ перегляду

о графічного представлення стану пацієнта на основі його МКФ-профілю (до та після курсу реабілітації)

о динаміку зміни ступеню відхилень від норми по МКФ-доменам 3 відповідною їх ієрархічною структурою та 3 представленням у кількісному та графічному вигляді.

о значень реабілітаційного потенціалу до курсу відновлення та інтегрального реабілітаційного показнику, що характеризують узагальнений стан пацієнта

о ефективності реабілітації, як у відсотковому представленні так і у словесній лінгвістичній шкалі.

- у управління

о вибір обсервацій пацієнта, які застосовувати для оцінювання.

о вибір показників, які використовувати для відповідних обчислень, що надає змогу проводити більш комплексний аналіз та виявляти проблемні аспекти. Таким чином веб-інтерфейс системи надає користувачеві всі необхідні засоби для перегляду і управління в цілях дослідження динаміки зміну стану пацієнта та ефективності його реабілітації.

Обговорення. Всесвітня організація охорони здоров'я (ВОО3) ставить своїм завданням

\section{T. 110
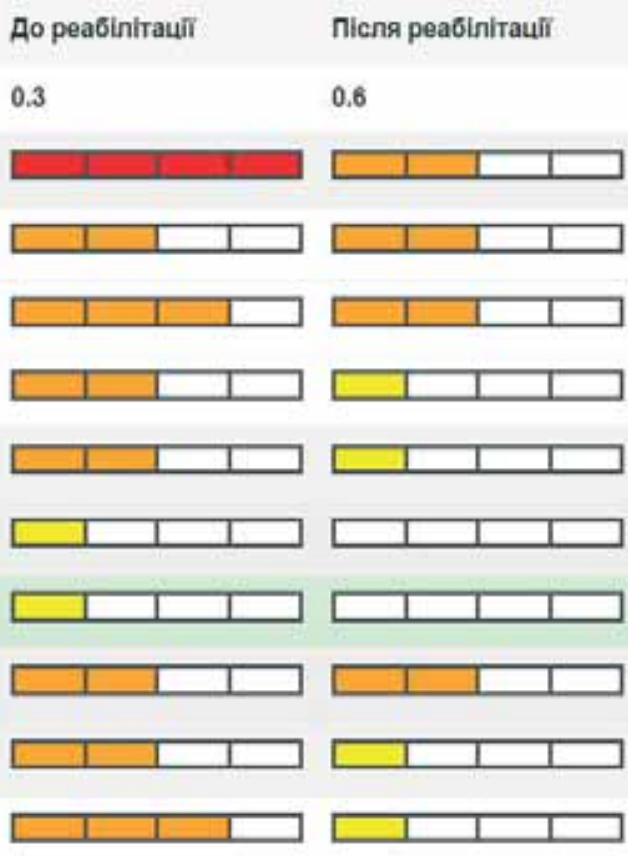

3 міна
$+100 \%$
+2
+0
+1
+1
+1
+1
+1
+0
+1
+2

Рис. 4. Користувацьий інтерфейс підсистеми оцінки ефективності реабілітаційних заходів 
впровадження МКФ в практику медичної та соціальної реабілітації, збір даних про інвалідності 3 використанням МКФ, створення комп'ютерних програм i мобільних додатків для практичного використання МКФ i підвищення якості та доступності реабілітації [15]. Застосування МКФ, як індикативного показника роботи кожного фахівця, дозволяє об'єктивно оцінити ефективність проведених лікувальних заходів, визначити реабілітаційний потенціал, прогноз відновлення порушених функцій, досягнення короткострокових і довгострокових цілей. Таким чином, використання МКФ є важливою частиною процесу визначення реабілітаційного потенціалу $[8,13,20,22]$. Слід відзначити, що необхідність використання МКФ в реабілітації пацієнтів як інструмент, що дозволяє охопити не тільки медичну, а й соціальну сторону реабілітації [12].

Створення та застосування програмного інструментарію для оцінки загального стану пацієнта на основі принципів МКФ з використанням сучасних методів обстеження пацієнта, прийнятих професійним співтовариством клінічних тестів допоможе мультидисциплінарній команді в складанні реабілітаційного діагнозу i у визначенні більш точного реабілітаційного потенціалу, що дозволить забезпечити більш високу ефективність медичної реабілітації в цілому $[7,10,18,21]$.

Розроблена програмна система оцінки ефективності реабілітаційних заходів на основі МКФ-профілей пацієнтів була перевірена на вхідних даних, що представлені в [17] i дала аналогічні результати. Це свідчить про те, що даний програмний продукт реалізовує відповідну методику та може застосовуватись безпосередньо на практиці для встановлення індикативного значення реабілітаційного потенціалу пацієнта та оцінки ефективності його реабілітації .

Зазначимо, що якщо у пацієнта низький реабілітаційний потенціал і поганий реабілітаційний прогноз, тоді при плануванні програми реабілітації варто враховувати можливість реадаптації пацієнта до наявного дефекту [17]. Основні принципи реабілітації включають в себе ранній початок проведення реабілітаційних заходів, етапність, комплексність, мультидисциплінарний підхід, індивідуалізацію, тривалість, безперервність, наступність, соціальну спрямованість і активну участь пацієнта.

\section{Висновки.}

Використання створеної програмної системи оцінки ефективності реабілітації на основі МКФпрофілей пацієнтів дозволяє оцінити реабілітаційний потенціал у кожного конкретного пацієнта, визначить його потребу в реабілітаційних послугах, відстежить динаміку i оцінити ефективність відновного лікування та реабілітації в цілому.

Перспективи подальших досліджень. На практиці можуть виникати обернені задачі(1)-(5), коли необхідно знайти такі показники нижнього рівня, які найбільш негативно впливають на показники верхніх рівнів, тобто є критичними - такими, що вимагають суттєвого реагування. Розв'язок цієї задачі може дозволити визначати більш оптимальну стратегію для максимальної реалізації реабілітаційного потенціалу.

Додаткова інформація.

Опубліковані матеріали на мають конфлікту інтересів.

Подяка. Дослідження виконано при підтримці гранту Національного фонду досліджень України за договором від 07.05.2021 p. № 159/01/0245 «Трансдисциплінарна інтелектуальна інформаційноаналітична система супроводження процесів реабілітації при пандемії (TISP)»

\section{Список літератури}

1. Бодрова Р. А., Аухадеев Э. И., Ахунова Р. Р., Хусаинова Э. Р. Подходы к выбору технических средств реабилитации с помощью МКФ. Физическая u реабилитационная медищина, медицинская реабилитация. 2019. Т. 4, № 4. С. 64-71.

2. Booch G., Maksimchuk R. A., Engle M. W., Young B. J., Conallen J., Houston K. A. Object-Oriented Analysis And Design With Applications: Third Edition. Addison-Wesley, 2007. P. 717.

3. Broy M. Mathematical System Models as a Basis of Software Engineering. Berlin: Springer, 1995. P. 292.

4. Chadwick J., Snyder T., Panda H. Programming ASP. NET MVC 4. O’Reilly Media, 2012. P. 492.

5. Eckerson W. Three Tier Client/Server Architectures: Achieving Scalability, Performance, and Efficiency in Client Server Applications. Open Information Systems. 1995. № 3. P. 46-50.

6. Fowler M. Patterns of Enterprise Application Architecture. Addison Wesley, 2003. P. 560.

7. Иванова Г.Е., Мельникова Е.В., Шамалов Н.А., Бодрова Р.А., Шмонин А.А., Суворов А.Ю., Нырков Г.В., Тулупов Д.О. Использование МКФ и оценочных шкал в медицинской реабилитации. Вестник восстановительной медицины. 2018. № 3. С. 14-20.

8. Jacob T. The implementation of the ICF among Israeli rehabilitation centers-the case of physical therapy. Physiotherapy theory and practice. 2013. Vol. 29, № 7. P. 536-46.

9. Jahan A., Ellibidy A. A review of conceptual models for rehabilitation research and practice. Rehabil Sci. 2017. Vol. 2, № 2. P. 46-53.

10. Leonardi M., Fheodoroff K. Goal Setting with ICF (International Classification of Functioning, Disability and Health) and Multidisciplinary Team Approach in Stroke Rehabilitation. In: Platz T. (eds) Clinical Pathways in Stroke Rehabilitation. Springer, Cham. 2021. P. 35-56.

11. Лорер В.В., Жукова Т.Н. Применение Международной классификации функционирования, ограничений жизнедеятельности и здоровья в оценке комплексной реабилитации инвалидов. Клиническая $u$ специальная психология. 2017. Том. 6, № 3. С. 116-134.

12. МельниковаЕ.В., Буйлова Т.В.,БодроваР.А.,Шмонин А. А., Мальцева М. Н., Иванова Г. Е. Использование международной классификации функционирования (МКФ) в амбулаторной и стационарной медицинской реабилитации: инструкция для специалистов. Вестник Восстановительной медицины. 2017. № 6 (82). С.7-20. 
13. Pernambuco A. P., Lana R. D., Polese J. C. Knowledge and use of the ICF in clinical practice by physiotherapists and occupational therapists of Minas Gerais. Fisioterapia e Pesquisa. 2018. Vol. 25, № 2. P134-142.

14. Rauch A., Cieza A., Stucki G. How to apply the international classifcation of functioning, disability and health (ICF) for rehabilitation management in clinical practice. Eur J Phys Rehabil Med. 2008. Vol. 44, № 3. P. 329-342.

15. Шмонин А.А. Совершенствование реабилитационных мероприятий и методов трансляционных исследований при церебральном инсульте на основе классификаций функционирования и ограничения жизнедеятельности: дис. д-ра мед. наук. СанктПетербург, 2019. 462 с.

16. Шошмин А.В., Пономаренко Г.Н., Бесстрашнова Я.К., Черкашина И.В. Применение Международной классификации функционирования, ограничений жизнедеятельности и здоровья для оценки эффективности реабилитации: методология, практика, результаты. Bопросы курортологии, физиотерапии $u$ лечебной физической культуры. 2016. Т.93, № 6. С. 1220.

17. Склянная К. А. Оценка прогностических факторов восстановления двигательной функции у пациентов в резидуальном периоде острого нарушения мозгового кровообращения в процессе кинезиотерапии: дис. канд. мед. наук. 2017. 180 C.

18. Steiner W. A., Ryser L., Huber E., et al. Use of the ICF model as a clinical problem-solving tool in physical therapy and rehabilitation medicine. Phys Ther. 2002. Vol. 82, № 11. P. 1098-1107.

19. Stucki G., Cieza A., Melvin J. The international classification of functioning, disability and health: a unifying model for the conceptual description of the rehabilitation strategy. J Rehabil Med. 2007. № 39. P. 279-285.

20. Stucki G., Ewert T., Cieza A. Value and application of the ICF in rehabilitation medicine. Disability and Rehabilitation. 2002. Vol. 24, № 17. P. 932-938.

21. Verhoef J., Toussaint P. J., Putter H., Schonk J., Vliet Vlieland T. P. M. The impact of introducing an ICF-based rehabilitation tool on staff satisfaction with multidisciplinary team care in rheumatology: an exploratory study. Clin Rehabil. 2008. Vol. 22, №1. P. 23-37.

22. Zhang T., Liu L., Xie R., Peng Y., Wang H., Chen Z., et al. Value of using the international classification of functioning, disability, and health for stroke rehabilitation assessment: A multicenter clinical study. Medicine (Baltimore). 2018. Vol. 97, № 42. P. 1-7.

\section{References}

1. Bodrova RA, Aukhadeev EI, Akhunova RR, Khusainova ER. Approaches to the technical means of rehabilitation selection using the ICF // Physical and rehabilitation medicine, medical rehabilitation. - 2019. - Vol. 1. - N. 4. - P. 64-71. (in Russian) doi: 10.36425/2658-6843-2019-4-64-71

2. Booch G., Maksimchuk RA, Engle MW, Young BJ, Conallen Jimm, Houston KA. Object-Oriented Analysis And Design With Applications: Third Edition, AddisonWesley, 2007. P. 717.

3. Broy M. Mathematical System Models as a Basis of Software Engineering. Berlin : Springer, 1995. P. 292.

4. Chadwick J., Snyder T., Panda H. Programming ASP. NET MVC 4. O’Reilly Media, 2012. P. 492.
5. Eckerson W. Three Tier Client/Server Architectures: Achieving Scalability, Performance, and Efficiency in Client Server Applications // Open Information Systems. 1995. - №. 3. - pp. 46-50.

6. Fowler M. Patterns of Enterprise Application Architecture. Addison Wesley, 2003. P. 560.

7. Ivanova GE, Melnikova E.V., Shamalov N.A., Bodrova R.A., Shmonin A.A. et al. Using the ICF and rating scales in medical rehabilitation. Vestnik vosstanovitel 'noj mediciny'. 2018;3(85): 14-20. (in Russian)

8. Jacob T. The implementation of the ICF among Israeli rehabilitation centers-the case of physical therapy. Physiotherapy theory and practice. 2013; 29(7):536-46. DOI: $10.3109 / 09593985.2013 .765935$

9. Jahan A, Ellibidy A. A review of conceptual models for rehabilitation research and practice. Rehabil Sci. 2017;2(2):46-53.

10. Leonardi M., Fheodoroff K. Goal Setting with ICF (International Classification of Functioning, Disability and Health) and Multidisciplinary Team Approach in Stroke Rehabilitation. In: Platz T. (eds) Clinical Pathways in Stroke Rehabilitation. Springer, Cham. 2021. doi:10.1007/978-3030-58505-1_3

11. Lorer VV, Zhukova TN. Application of the International Classification of Functioning, Disability and Health in assessment of integrated rehabilitation of disabled people [Elektronnyi resurs]. Clinical Psychology and Special Education [Klinicheskaia i spetsial'naia psikhologiia], 2017, vol. 6, no. 3, pp. 116-134. doi: 10.17759/ psycljn.2017060307 (In Russ., abstr. in Engl.)

12. Melnikova EV, Builova T.V., Bodrova R.A., Shmonin A.A., Maltseva M.N., Ivanova G.E. Use of the international classification of functioning (ICF) in outpatient and inpatient medical rehabilitation: instruction for specialists. Vestnik vosstanovitel ’noj mediciny`. 2017;6(82). (in Russian)

13. Pernambuco AP, Lana RD, Polese JC. Knowledge and use of the ICF in clinical practice by physiotherapists and occupational therapists of Minas Gerais. Fisioterapia e Pesquisa. 2018 Jun;25(2):134-42. DOI: 10.1590/18092950/16765225022018

14. Rauch A, Cieza A, Stucki G. How to apply the international classifcation of functioning, disability and health (ICF) for rehabilitation management in clinical practice. Eur J Phys Rehabil Med. 2008;44:329-42.

15. Shmonin AA. Improvement of rehabilitation measures and methods of translational research in cerebral stroke based on classifications of functioning and disability: doctoral dissertation (medical sciences). S. Petersburg, 2019. P. 462. (in Russian)

16. Shoshmin AV, Ponomarenko G.N., Besstrashnova Y.K., Cherkashina I.V. The application of the International Classification of functioning, disability and health for the evaluation of the effectiveness of rehabilitation: methodology, practical experience, results. Voprosy kurortologii, fizioterapii i lechebnoj fizicheskoj kul'tury. 2016; Vol.93, 6: 12-20. doi: 10.17116/kurort2016612-20. (in Russ.).

17. Sklyannaya KA. Assessment of prognostic factors of restoration of motor function in patients in the residual 
period of acute cerebrovascular accident in the course of kinesiotherapy: $\mathrm{PhD}$ dissertation (medical sciences). Perm, 2017. P. 180. (in Russian)

18. Steiner WA, Ryser L, Huber E, et al. Use of the ICF model as a clinical problem-solving tool in physical therapy and rehabilitation medicine. Phys Ther. 2002;82(11):10981107. DOI: $10.1093 / \mathrm{ptj} / 82.11 .1098$

19. Stucki G, Cieza A, Melvin J. The international classification of functioning, disability and health: a unifying model for the conceptual description of the rehabilitation strategy. J Rehabil Med. (2007) 39:279-85. doi: 10.2340/16501977-0041

20. Stucki G., Ewert T., Cieza A. Value and application of the ICF in rehabilitation medicine. Disability and
Rehabilitation. 2002; 24(17): 932-938. PMID 12523361. doi:10.1080/09638280210148594

21. Verhoef J, Toussaint PJ, Putter H, Zwetsloot-Schonk JHM, Vliet Vlieland TPM. The impact of introducing an ICF-based rehabilitation tool on staff satisfaction with multidisciplinary team care in rheumatology: an exploratory study. Clin Rehabil. (2008) 22:23-37. doi: $10.1177 / 0269215507079845$

22. Zhang T, Liu L, Xie R, Peng Y, Wang H, Chen Z, et al. Value of using the international classification of functioning, disability, and health for stroke rehabilitation assessment: A multicenter clinical study. Medicine (Baltimore). 2018; 97(42):1-7. DOI:10.1097/MD.0000000000012802 PMID: 30334972

\section{EVALUATION OF THE EFFECTIVENESS OF REHABILITATION MEASURES BASED ON ICF ASSESSMENT SHEETS OF PATIENTS}

\section{Gorborukov V. V.}

Rehabilitation is an important health strategy and is seen as a set of measures aimed at helping people with disabilities to achieve and maintain optimal functioning in interaction with the environment. Determining the rehabilitation potential of patients and assessing the effectiveness of rehabilitation is a necessary condition for the formation of the correct rehabilitation strategy. The International Classification of Functioning, Disability and Health (ICF) is a modern international tool that defines the principles of forecasting rehabilitation results, assessing rehabilitation potential and building rehabilitation programs. The implementation of these principles allows to make the rehabilitation process transparent, which helps to improve the quality of medical care. But in addition to evaluation on these scales, the necessary method of determining on the basis of the relevant indicators of the integral value of the rehabilitation potential of the patient, his ability to recover and the effectiveness of rehabilitation.

The purpose of the research was to develop a scientific and methodological approach to determining the effectiveness of rehabilitation measures based on ICF assessment sheet of patients and the software implementation of this approach in the form of information and analytical system

The current state of methods for assessing the rehabilitation potential and effectiveness of rehabilitation on the basis of the international ICF standard is considered. The method of evaluation of rehabilitation efficiency on the basis of calculation of rehabilitation integrated indicator from the point of view of possibility of its improvement and formalization in the form of a certain mathematical model is analyzed. The software of the rehabilitation efficiency assessment was creating with the help of appropriate design patterns and on the basis of object-oriented approach.

The method of evaluating the effectiveness of rehabilitation measures has been improved and its mathematical model has been created, which allows to evaluate the complex result of rehabilitation, using the ICF domains. A software system for assessing the effectiveness of rehabilitation based on ICF assessment sheet of patients has been developed, which allows for a comprehensive analysis of the process of their recovery. In particular, the system provides the following opportunities: to determine the rehabilitation potential of the patient, which allows to assess his potential for recovery; to establish a rehabilitation integrated indicator after the rehabilitation course, which allows to determine the level of realization of the initial rehabilitation potential and the degree of restoration of compensatory opportunities; to analyze the dynamics of changes in ICF domains and identify the most problematic areas.

The use of the established software system for assessing the effectiveness of rehabilitation based on ICF assessment sheet of patients allows to assess the rehabilitation potential of each patient, determine his need for rehabilitation services, monitor the dynamics and evaluate the effectiveness of rehabilitation.

Key words: international classification of functioning, effectiveness of rehabilitation, rehabilitation potential, software system. 